\title{
Implicit and Explicit Associations with Erotic Stimuli in Women with and Without Sexual Problems
}

\author{
Jacques J. D. M. van Lankveld ${ }^{1}$ (1) - Myrthe Bandell ${ }^{2}$ Eva Bastin-Hurek ${ }^{3}$. \\ Myra van Beurden ${ }^{1} \cdot$ Suzan Araz $^{1}$
}

Received: 24 December 2016 / Revised: 4 December 2017 / Accepted: 10 January 2018 / Published online: 20 February 2018

(C) The Author(s) 2018. This article is an open access publication

\begin{abstract}
Conceptual models of sexual functioning have suggested a major role for implicit cognitive processing in sexual functioning. The present study aimed to investigate implicit and explicit cognition in sexual functioning in women. Gynecological patients with $(N=38)$ and without selfreported sexual problems $(N=41)$ were compared. Participants performed two Single-Target Implicit Association Tests (ST-IAT), measuring the implicit association of visual erotic stimuli with attributes representing, respectively, valence and motivation. Participants also rated the erotic pictures that were shown in the ST-IATs on the dimensions of valence, attractiveness, and sexual excitement, to assess their explicit associations with these erotic stimuli. Participants completed the Female Sexual Functioning Index and the Female Sexual Distress Scale for continuous measures of sexual functioning, and the Hospital Anxiety and Depression Scale to assess depressive symptoms. Compared to nonsymptomatic women, women with sexual problems were found to show more negative implicit associations of erotic stimuli with wanting (implicit sexual motivation). Across both groups, stronger implicit associations of erotic stimuli with wanting predicted higher level of sexual functioning. More positive explicit ratings of erotic stimuli predicted lower level of sexual distress across both groups.
\end{abstract}

Jacques J. D. M. van Lankveld

jacques.vanlankveld@ou.nl

1 Faculty of Psychology and Educational Sciences, Open University of the Netherlands, Valkenburgerweg 177, 6419 AT Heerlen, The Netherlands

2 Department of Gynecology, Albert Schweitzer Hospital, Dordrecht, The Netherlands

3 GGZ Keizersgracht, Amsterdam, The Netherlands
Keywords Female sexual dysfunction · Implicit cognition $\cdot$ Dual-process model $\cdot$ Implicit association

\section{Introduction}

Psychological models of sexual dysfunction in physically healthy individuals suggest an important causal role for cognitive processes (Barlow, 1986; Janssen, Everaerd, Spiering, \& Janssen, 2000; van Lankveld et al., 2015) that operate at different levels of awareness and regulatory control (Corr, 2010; Schneider \& Shiffrin, 1977), including implicit and automatic processes. Conscious access for the individual to automatic cognitive processes is limited (Fitousi \& Wenger, 2011; Kahneman, 1973). While early cognitive theories of sexual dysfunction (Barlow, 1986) assigned a central role to controlled cognitions, of which the individual can be consciously aware, more recent models (Janssen et al., 2000) additionally emphasize the contribution of automatic appraisal of sex-relevant information to sexual functioning, of which the individual is not necessarily aware. In the cognitive interference model of sexual dysfunction, Barlow postulated an important role, next to affective factors, for cognitive interference and distraction in dysfunctional sexual performance. Compared with nonsymptomatic men, men with sexual dysfunction would be more preoccupied with thoughts about dysfunctional erectile performance, focus their attention less on the erotic stimuli, react with more negative affect and physiological anxiety, and expect personal failure during the sexual encounter. When they, subsequently, experience problems with their sexual performance, they see this as confirming their negative expectations. This experience reinforces the vicious circular process that results in sexual dysfunction. Although Barlow mainly reviewed experimental research among men to support his conceptual model 
(Abrahamson, Barlow, \& Abrahamson, 1989; Bach, Brown, \& Barlow, 1999; Barlow, Sakheim, \& Beck, 1983; Beck \& Barlow, 1986a, b; Mitchell, DiBartolo, Brown, \& Barlow, 1998; Weisberg, Bach, \& Barlow, 1995), the basic tenets of Barlow's model are also assumed to account for problems with impaired sexual arousal in women (Laan \& Everaerd, 1995; Wiegel, Scepkowski, \& Barlow, 2007). The model later received ample empirical support from cross-sectional studies in which controlled cognitions were assessed using self-report instruments, including sexual beliefs, and sexual self-schemata (Andersen, Cyranowski, \& Espindle, 1999; Nobre \& Pinto-Gouveia, 2009; Peixoto \& Nobre, 2014, 2016; Quinta Gomes \& Nobre, 2012). Men and women suffering from sexual dysfunction consistently reported endorsing more negative controlled cognitions than sexual healthy individuals before, during, and following - mostly partneredsexual activity. However, due to the cross-sectional nature of the data in these studies, one cannot eliminate the possibility that such negative conscious thoughts are a consequence rather than a cause of sexual dysfunction. To determine causality at this point, experimental manipulation would be required.

Janssen et al. (2000) introduced automatic cognition in their information-processing model as an additional determinant of arousal-related sexual dysfunction. Janssen et al. do not explicitly state whether or not the model accounts for both male and female sexual arousal. A crucial assumption in this model is that perceived erotic stimuli are coded by the individual as carrying either sexual or nonsexual meaning. This attribution of meaning subsequently determines whether the stimulus serves to activate or to inhibit sexual arousal, at both the physiological and the subjective level. The model further postulates that this encoding and evaluation of erotic stimuli occurs both at the conscious/controlled and at the unconscious/automatic level of processing. Moreover, it posited that erotic stimuli, even when they are not consciously perceived, would be capable of automatically initiating the efferent physiological process underlying the genital sexual response. Experimental research (Macapagal \& Janssen, 2011; Spiering, Everaerd, \& Janssen, 2003; Spiering, Everaerd, Karsdorp, Both, \& Brauer, 2006) provided the first empirical support for the model in both men and women.

The demonstration in previous research that both conscious and unconscious negative cognitions are capable of hindering sexual arousal calls for further explanation of the mechanism underlying this effect. Hypothetical working mechanisms include, among others, the cognitive processing-capacity model of sexual arousal (de Jong, 2009; van Lankveld, 2010; van Lankveld \& van den Hout, 2005) and dual-process theory (Evans \& Frankish, 2009). Germane to the processing-capacity model is the fundamentally limited capacity of the working memory function of the brain to simultaneously process multiple bits of information (Baddeley, 1992; Dehaene, 2014). Whether perception of erotic stimuli produces genital sexual responses has been found to depend on the availability of information-processing capacity in several experimental studies among both men and women, in which double-task or distraction paradigms were used (Adams, Haynes, \& Brayer, 1985; Elliott \& O'Donohue, 1997; Geer \& Fuhr, 1976; Salemink \& van Lankveld, 2006; van Lankveld \& Bergh, 2008; van Lankveld \& van den Hout, 2004). Genital responses during erotic stimulation were correspondingly lower when a concurrent cognitive task captured incrementally larger parts of the available processing capacity (but see: Abrahamson, Barlow, Sakheim, Beck, \& Athanasiou, 1985; Janssen, Everaerd, van Lunsen, \& Oerlemans, 1994, for studies suggesting that cognitive distraction facilitated erectile responses). Concurrent processing of erotic and nonerotic stimuli thus appears to reduce the cognitive capacity that is - maybe even predominantly —needed for the processing of erotic stimuli.

Dual-process models might offer another explanation for this mechanism. These models assign a pivotal role to working memory capacity in determining the relative impact of cognitions operating at different levels of awareness (Hofmann \& Friese, 2008; Strack \& Deutsch, 2004). Essentially, they postulate that contextual factors, including-among others-fatigue and intoxication by alcohol or other psychotropic agents, impose constraints on the functioning of the working memory. By doing so the regulatory function of conscious, controlled cognizing is suppressed, because the latter requires sufficient processing resources. Limiting the capacity of the working memory thus clears the way for unconscious, automatic cognitive processes to determine behavioral outcome. These latter processes are able to digest vast amounts of information from a broad perceptual field and require only minimal working memory capacity. A dual-process framework might thus combine the constructs of conscious cognitive interference (Barlow, 1986), conscious and unconscious information-processing (Janssen et al., 2000), and cognitive processing capacity (de Jong, 2009; van Lankveld, 2010) that were previously proposed as separate determinants of sexual responding and sexual dysfunction. Implicit attitudes have been suggested to develop through different pathways, reflecting both deeply ingrained cultural stereotypes (Nosek et al., 2009; Steffens \& Buchner, 2003) and the result of learning experiences in individual personal history (Gonzalez, Dunlop, \& Baron, 2017), as a result of frequent pairings of stimuli with the same emotional state (Gawronski \& Bodenhausen, 2006). Adding implicit cognitive mechanisms to psychological models featuring explicit and conscious cognition, has been shown to increase their explanatory power in other fields, including affective disorders, alcohol-related disorder, and eating disorder (see Roefs et al., 2011, for a review).

Automatic cognitive associations with erotic stimuli were thus far compared in women with and without sexual 
dysfunction in a small number of studies. In one study implicit associations of vaginal penetration stimuli with, respectively, disgust and threat were assessed using two singletarget Implicit Association Tasks (ST-IAT; Bluemke \& Friese, 2008; Borg, de Jong, \& Weijmar Schultz, 2010). Compared with healthy women, women with sexual pain disorder and lifelong vaginismus were found to harbor enhanced automatic sex-disgust associations. In another study the strength of the implicit associations of vaginal penetration stimuli with positive valence was measured using a ST-IAT (Brauer et al., 2011). Compared with nonsymptomatic women, women with acquired hypoactive sexual desire disorder revealed less positive (but not more negative) implicit associations with sexual stimuli.

In addition to implicit associations with valence, that is how strongly they like or dislike sex, individuals with and without sexual dysfunction might differ with regard to the strength of their sexual motivation, that is: how strongly they want sex, both at the explicit and implicit cognitive level. A similar distinction between liking (association with positive valence) and wanting (see also for a behavioral neuroscience framework: Romer Thomsen, Whybrow, \& Kringelbach, 2015) was found in individuals addicted to illegal drugs (Robinson \& Berridge, 1993, 2008) and in individuals with disordered eating behavior (Tibboel et al., 2011). A discrepancy between hedonic value and craving reactions, connected to the substance of interest, was demonstrated between patients and healthy controls. Although both were found to have similar levels of implicit liking of, respectively, the psychotropic drug and fatty food, they exhibited stronger implicit wanting toward drug and food.

Based on these notions we have used two versions of the ST-IAT in the present study that measure the implicit associations of sexual stimuli with, respectively, valence ("liking") and motivation ("wanting"). The ST-IAT is a modified, single-target version of the Implicit Association Test (IAT; Greenwald, McGhee, \& Schwartz, 1998). In the IAT two opposing target categories are used that are naturally occurring opposites (e.g., men vs. women; animate vs. inanimate). For sexual stimuli, however, such naturally occurring opposing category is not available. For this reason only sexual stimuli are used as target category. Both the ST-IAT (Bluemke \& Friese, 2008) and the IAT (Houben \& Wiers, 2008; Nosek, Greenwald, \& Banaji, 2005) possess satisfactory psychometric characteristics.

Previously, implicit liking and wanting using two STIATs were investigated in male patients with and without sexual dysfunction from a urological outpatient clinic (van Lankveld et al., 2015). Although both groups significantly differed on the implicit association of erotic stimuli with liking, the direction of the observed differences was unexpected: sexually dysfunctional men harbored more positive implicit associations with erotic stimuli than healthy men. Implicit wanting did not differentiate between both groups. In another study of our group among male urological patients with and without sexual problems, lower levels of sexual functioning again came with stronger automatic sex-positive association. This effect was significantly higher in the lower age group. Additionally, an independent negative relationship was found in younger men between explicit sex-liking associations and sexual functioning (van Lankveld et al., 2017).

In sum, in the present study implicit and explicit associations of erotic stimuli with liking and wanting were investigated in women with and without sexual problems. As a secondary research aim, age will be exploratively investigated as a moderating factor. In addition to group differences, we will also investigate the association of implicit and explicit sexual cognition with continuous measures of sexual functioning and sexual distress. Based on previous research into the role of implicit associations in sexual functioning in women (Borg et al., 2010; Brauer et al., 2011) and men (van Lankveld et al., 2015), we test the following hypotheses: (1) women with sexual problems will show weaker implicit liking and wanting associations with erotic stimuli than functional women, as well as less positive explicit evaluations of erotic stimuli; (2) positive implicit associations of erotic stimuli with liking and wanting will be associated with higher self-reported level of sexual functioning and lower level of sexual distress; and - similarly - (3) positive explicit ratings of erotic stimuli and positive explicit attitudes toward sexuality will be associated with higher self-reported level of sexual functioning and lower level of sexual distress.

\section{Method}

\section{Participants}

Participants in the study were women with sexual complaints visiting an outpatient gynecology clinic for sexological treatment with or without concomitant gynecological complaints and women visiting the same hospital for other gynecological complaints, including contraception advice, subfertility, and menstrual cycle abnormalities. Exclusion criteria were: major psychopathology (Hospital Anxiety and Depression Scale total score > 15; Spinhoven et al., 1997), the use of SSRI's, antipsychotic and other psychopharmacological medication, and age younger than 18 years. Participants were required to have thorough mastery of the Dutch language. This was deemed necessary for participants to be able to answer all relevant questions in the study and to perform the computer tasks. None of the tested participants were excluded. Ethical clearance for the study was obtained from the hospital's ethical review board. 


\section{Instruments}

\section{Sexual Functioning}

Female Sexual Function Index (FSFI) The FSFI (Rosen et al., 2000) is a 19-item self-report questionnaire for assessing female sexual functioning that is organized in six subscales measuring, respectively, sexual desire, sexual arousal, lubrication, orgasmic function, sexual satisfaction, and sexual pain. Subscale scores are summated to form a global index of sexual functioning (FSFI total score; scoring range 4-95). Participants provided answers on, respectively, 5- and 6-item scales, with higher scores indicating better sexual functioning. In psychometric research, the factor structure was confirmed of the English version (Opperman, Benson, \& Milhausen, 2013) and the Dutch language version (ter Kuile, Brauer, \& Laan, 2006). The internal consistency of the FSFI was found to be excellent (Cronbach's $\alpha$ 's $>0.82$ ), and testretest reliability was high for all subscales $(r=0.79-0.86)$ and for the total scale $(r=0.88$; (Rosen et al., 2000). In the present study, the internal consistency was found to be ranging from acceptable for the orgasm subscale (Cronbach's $\alpha=.63)$ to excellent for the sexual desire subscale $(\alpha=.90)$.

Female Sexual Distress Scale (FSDS) For the measurement of sexual problem-related distress, the FSDS is used (Derogatis, Rosen, Leiblum, Burnett, \& Heiman, 2002) that comprises 12 items. It is organized in a single scale and was found to have very good reliability in healthy and sexually dysfunctional women, both regarding internal consistency (Cronbach's $\alpha$ 's, respectively, $\alpha=.86$ and .88) and test-retest reliability $(r=.91)$. The Dutch language version was validated in Dutch female samples (ter Kuile et al., 2006) and was found to have excellent reliability (Cronbach's $\alpha=.93$ ). In the present study, the internal consistency was found similarly excellent, with Cronbach's $\alpha=.96$.

\section{Implicit Associations with Sexual Stimuli}

Single-Target Implicit Association Test (ST-IAT) The ST-IAT is a computer-based reaction time test to measure the magnitude of the implicit associations of a single-target category (erotic stimuli) with, respectively, liking (valence) and wanting (motivation). It is a modified version of the Implicit Association Test (IAT; Greenwald et al., 1998) and has comparable psychometric characteristics (Karpinski \& Steinman, 2006). The erotic target in the liking and the wanting ST-IATs was represented by four pictures of heterosexual interaction (Borg et al., 2010), selected from the International Affective Picture System (Lang, Bradley, \& Cuthbert, 1999). ${ }^{1}$ Each

\footnotetext{
1 Selected erotic pictures were IAPS-numbers 4658, 4659, 4664, and 4680 .
}

picture depicted a female and a male actor engaging in explicit sexual activity, without showing full close-up shots of the genitals. Female breasts were fully visible, whereas the male actors' penis was not visible. Participants were instructed to assign the words and pictures appearing in the center of a laptop computer screen to one of two categories, using the " $\mathrm{z}$ " and " $\mathrm{m}$ " keyboard keys. The attribute categories for the liking ST-IAT were "positive" (represented by the words humor, health, gift, and peace [in Dutch: humor, gezondheid, kado, vrede]) and "negative" (represented by the words hatred, war, disease, and pain [in Dutch: haat, oorlog, ziekte, pijn]). The labels of the attribute categories ("positive" and "negative") were continuously shown in the upper left and right corners of the screen. Upon a correct response, placing the presented stimuli in the designated target or attribute category by pressing the key in accordance with the instruction, the next stimulus was presented. Following an incorrect response, error feedback was given using a red $\mathrm{X}$ that replaced the stimulus and remained on the screen until the correct response was given. Table 1 displays the setup of the ST-IAT procedure. To familiarize participants with the procedure, the ST-IAT started with a practice run with the attribute stimuli only. Next, there were two blocks of 48 trials, each starting with a practice block of 12 trials in which both erotic pictures and positive and negative attribute words were randomly presented, followed by a test block of 36 trials. Within both the practice and test blocks, the numbers of responses on both response keys were unequal. Within the erotic-positive test block, participants made 24 key presses on the right key and 12 on the left key. In the erotic-negative test block this was reversed, with 12 right-key and 24 left-key presses being made. The same target and attribute stimuli were used in the practice and test trials (Nosek et al., 2005). In one block erotic pictures and positive words were mapped on the same response key ("sex-positive" combination), whereas in the other block erotic pictures and negative words shared the same response key ("sex-negative" combination). The order of presentation of sex-positive and sex-negative blocks was counterbalanced across participants. Because performance is assumed to be faster when the association between the target and the attribute is congruent with the participant's representational network than when this association is incongruent, one of both combinations (sex-positive or sex-negative) is expected to yield briefer reaction times. The attribute categories for the wanting ST-IAT were "I want" (represented by the same stimulus words as were used in the liking STIAT) and "I do not want" (also using the same words). The labels of the attribute categories ("I want" and "I do not want") were continuously shown in the upper left and right corners of the screen. The same erotic pictures were used as in the liking ST-IAT. The next stimulus was presented irrespective of the selected response key, to emphasize the more personalized nature of this ST-IAT version (Olson \& Fazio, 
Table 1 Sequence of trial blocks in the sex-liking and wanting ST-IAT

\begin{tabular}{lllll}
\hline Block & No. of trials & Function & Items assigned to left-key response & Items assigned to right-key response \\
\hline 1 & 16 & Attribute practice & Positive (8) & Negative (8) \\
2 & 12 & Practice & Positive (4) + erotic (4) & Negative (4) \\
3 & 36 & Test & Positive (12) + erotic (12) & Negative (12) \\
4 & 12 & Practice & Positive (4) & Negative (4) + erotic (4) \\
5 & 36 & Test & Positive (12) & Negative (12) + erotic (12) \\
\hline
\end{tabular}

Sequence of trial blocks in the wanting ST-IAT

\begin{tabular}{lllll}
\hline Block & No. of trials & Function & Items assigned to left-key response & Items assigned to right-key response \\
\hline 1 & 16 & Attribute practice & I want (8) & I don't want (8) \\
2 & 12 & Practice & I want (4) + erotic (4) & I don't want (4) \\
3 & 36 & Test & I want (12) + erotic (12) & I don't want (12) \\
4 & 12 & Practice & I want (4) & I don't want (4) + erotic (4) \\
5 & 36 & Test & I want (12) & I don't want (12) + erotic (12) \\
\hline
\end{tabular}

For half of the subjects, the positions of Blocks 2 and 3 are switched with those of Blocks 4 and 5, respectively

ST-IAT Single-Target Implicit Association Test

2004). The order of performance of the liking and wanting ST-IATs was fixed, with the liking ST-IAT used as the first task.

\section{Explicit Associations with Sexual Stimuli}

Explicit Evaluation scale of Erotic Stimuli (EEES) To index explicit cognitive associations with sexual stimuli, the same erotic pictures that were used in both ST-IATs were presented on a computer screen and participants evaluated each picture on two dimensions, using 5-point Likert scales (attractiveness [not at all to very attractive] and sexual excitement [not at all to very exciting]). Per participant mean rating scores across the four ST-IAT pictures were calculated for, respectively, "EEES-attractiveness" and "EEES-excitement." The EEES item scores were entered in a principal component analysis using varimax rotation. A single-factor solution was extracted, explaining $59.7 \%$ of the variance. In further analyses a sum score was used to index explicit cognitive ratings.

\section{Depression and Anxiety}

Hospital Anxiety and Depression Scale (HADS) The HADS was used to assess the exclusion criterion of the severity of depression and anxiety symptoms. It is a 14-item self-report questionnaire, specifically used in hospital and outpatient clinic settings (Zigmond \& Snaith, 1983). It is organized in two subscales for the domains of, respectively, anxiety and depression. High scores represent higher levels of anxiety and depression. The HADS has been found to possess satisfactory to high internal consistency in Dutch samples, with Cronbach's $\alpha$ ranging from .71 to .90 (Spinhoven et al., 1997). In the present study, the internal consistency was found to be good for the anxiety subscale (Cronbach's $\alpha=.68$ ) and satisfactory for the depression subscale $(\alpha=.68)$.

\section{Procedure}

All participants visited an outpatient gynecology clinic for clinical evaluation and treatment. Consecutive sexology patients of one of the authors (MB, gynecologist and fully registered sexologist, NVVS/FECSM) and a physical therapist, and general gynecology patients of two other gynecologists, who met the inclusion and exclusion criteria, were invited for participation in the study within a time period of four weeks. Patients who were interested received an information leaflet and an informed consent form. Those who wanted to give their consent immediately were allowed to participate in the testing directly following their visit to their gynecologist. After signing the informed consent form, participants were escorted to a quiet space and received further instructions. However, all invited participants were allowed to postpone their decision to participate; those who gave their consent at a later moment were scheduled for testing in a follow-up visit to the hospital within four weeks. Order of testing was: first, performance of the ST-IAT tasks and, subsequently, completion of online questionnaires (demographic questions, explicit ratings of the ST-IAT erotic pictures, FSFI, FSDS, and HADS).

\section{Statistical Analysis}

To index the implicit associations of erotic stimuli with liking and wanting, an improved D600 computation algorithm of 
Greenwald, Nosek, and Banaji (2003) was employed. Combined data of practice and test phases were used to calculate the D600 ST-IAT index. In this measure, reaction times (RT) below $400 \mathrm{~ms}$ were discarded and RTs above $2500 \mathrm{~ms}$ were replaced with $2500 \mathrm{~ms}$ before calculation of the mean RTs. RTs from error trials were replaced with the reaction time plus a 600 -ms penalty. The D600 index score was calculated as the difference score between the mean reaction times to the sex-positive and sex-negative combination blocks (sex-positive minus sex-negative), divided by the standard deviation calculated across all blocks with exception of the attribute practice block. Lower D600 scores thus indicate that erotic stimuli were stronger associated with liking and wanting.

Using $d=0.65$ as a conservative mean effect size estimate of IAT differences, based on group comparison studies (Nosek et al., 2005), we required 60 participants to obtain $80 \%$ statistical power of an independent-samples $t$ test, using $p<.05$.

Analyses were performed using SPSS version 22. The potentially confounding impact of age and of presentation order of ST-IAT phases was examined. The assumptions for statistical analyses were examined. To test Hypothesis 1, a MANOVA was performed with ST-IAT liking and wanting indices and EEES sum scores as dependent variables and sexual function status (with vs. without sexual problem) as between-subjects factor. To test Hypothesis 2, hierarchical linear regression analyses were performed with ST-IAT liking and wanting indices as independent variables and, respectively, sexual functioning (FSFI total score) and sexual distress (FSDS total score) as dependent variables. To test Hypothesis 3 , linear regression analyses were performed with EEES sum score as independent variable and, respectively, level of sexual functioning (FSFI total score) and sexual distress (FSDS total score) as dependent variables. Effect sizes and their 95\% confidence intervals were calculated (Steiger, 2004).

\section{Results}

\section{Preliminary Analyses}

Of 50 female patients who visited the outpatient clinic for sexual dysfunction and who met the inclusion criteria, 18 patients (36\%) participated. Of 200 gynecological patients who requested help for other complaints than sexual dysfunction, and who met the inclusion criteria, 61 (31\%) participated. Reasons for nonparticipation were not systematically recorded. Motivations given spontaneously included lack of time, inconvenience due to other appointments in the hospital and dislike of participation in research on sexual issues. Gynecological conditions of participants in the subgroup of women without a diagnosis of sexual dysfunction included contraception advice (10\%), subfertility (22\%), and menstrual cycle abnormalities (15\%). A substantial proportion of the gynecological patients who requested help for other complaints than sexual dysfunction also reported suffering from sexual complaints when completing the pertinent questions in the study questionnaires. Therefore, the final assignment to the subgroups of, respectively, women with and without sexual problems for the study was based on the participant's scores on, respectively, the FSFI and the FSDS. Participants in the sexual problem subgroup scored 26 or lower on the FSFI total scale and 12 or higher on the FSDS (ter Kuile et al., 2006). All participants but one who received a clinical diagnosis were thus included in the subgroup with sexual problems. Additionally, 21 women without initial diagnosis of sexual dysfunction were included in this subgroup. In the subgroup of women with a sexual problem, three women wanted to schedule the testing session at a later moment, due to time constraints. All women without sexual problems were tested immediately following their visit to the gynecologist. Demographic and medical characteristics of the study sample and subgroups are shown in Table 2.

Thirty-eight women were thus assigned to the group with sexual problems and 41 women to the group without sexual problems. Age was not significantly different in both groups ( $M_{\text {sexual_problem }}=35.5$ years versus $M_{\text {no_problem }}=36.2$ years $)$, $t=.25, d f=77, p>.05$, nor were they different with respect to relationship status and relationship duration.

The bivariate correlations of the implicit associations of erotic stimuli with liking and wanting and the explicit ratings of erotic stimuli are shown in Table 3. No significant correlations were found.

To check the effect of presentation order of the two STIAT versions, two hierarchical logistic regression analyses were conducted with sexual function status (with vs. without sexual problem) as criterion variable. In the first step, respectively, ST-IAT liking or ST-IAT wanting was entered as predictor variable; in the second step presentation order and the interaction term of presentation order with, respectively, ST-IAT liking or ST-IAT wanting were entered. Both analyses did not yield significant regression models in the second step, indicating the absence of an effect of presentation order. Presentation order was not used as a factor in further analyses.

\section{Implicit and Explicit Associations with Erotic Stimuli of Women with and Without Sexual Problem}

Descriptive statistics of implicit and explicit scores as a function of sexual function status are shown in Table 4. Two univariate outliers with extremely low scores ( $>2 \mathrm{SD}$ ) on the explicit ratings of the erotic pictures, one in each group, were not included in statistical analysis. No multivariate outliers were identified. 
Table 2 Demographic, medical, sexual, and psychological functioning characteristics of participants

\begin{tabular}{|c|c|c|c|c|c|c|}
\hline$\overline{\text { Demographics }}$ & \multicolumn{2}{|c|}{$\begin{array}{l}\text { Women without sexual problems } \\
(N=41) M(\mathrm{SD}) / \%\end{array}$} & \multicolumn{2}{|c|}{$\begin{array}{l}\text { Women with sexual problems } \\
(N=38) M(\mathrm{SD}) / \%\end{array}$} & \multicolumn{2}{|l|}{$\begin{array}{l}\text { Total }(N=79) \\
M(\mathrm{SD}) / \%\end{array}$} \\
\hline Age (years) & $36.2(11.3)$ & & $35.5(14.5)$ & & $35.8(12.9)$ & \\
\hline Steady relationship & & $88 \%$ & & $87 \%$ & & $87 \%$ \\
\hline Length of current sexual relationship (years) & $10.2(14.5)$ & & $11.5(11.4)$ & & $10.9(11.9)$ & \\
\hline \multicolumn{7}{|l|}{ Education level (highest achieved) } \\
\hline Elementary—lower secondary & & $20 \%$ & & $11 \%$ & & $15 \%$ \\
\hline Higher secondary-professional & & $61 \%$ & & $61 \%$ & & $61 \%$ \\
\hline College_-university & & $20 \%$ & & $29 \%$ & & $24 \%$ \\
\hline \multicolumn{7}{|l|}{ Gynecological diagnosis } \\
\hline Menopausal complaints & & $2 \%$ & & & & \\
\hline Infertility & & $22 \%$ & & $3 \%$ & & \\
\hline Cervical cysts & & $5 \%$ & & & & \\
\hline Vaginal condylomata & & $5 \%$ & & & & \\
\hline Menstrual cycle complaints & & $15 \%$ & & & & \\
\hline Lower abdominal pain & & $15 \%$ & & & & \\
\hline Urinary/fecal incontinence & & $2 \%$ & & $5 \%$ & & \\
\hline Contraception complaints & & $10 \%$ & & & & \\
\hline Fluor vaginalis & & $10 \%$ & & & & \\
\hline Prolactinoma & & & & $3 \%$ & & \\
\hline Lichen sclerosis & & & & $5 \%$ & & \\
\hline Pelvic floor disorder & & & & $5 \%$ & & \\
\hline \multicolumn{7}{|l|}{ Self-reported sexual problem type ${ }^{a}$} \\
\hline Sexual desire problem & & $0 \%$ & & $39 \%$ & & $23 \%$ \\
\hline Lubrication problem & & $0 \%$ & & $35 \%$ & & $21 \%$ \\
\hline Subjective sexual arousal problem & & $0 \%$ & & $35 \%$ & & $21 \%$ \\
\hline Orgasm problem & & $0 \%$ & & $15 \%$ & & $9 \%$ \\
\hline Sexual pain problem & & $6 \%$ & & $69 \%$ & & $43 \%$ \\
\hline \multicolumn{7}{|l|}{ Professional help for sexual problem } \\
\hline Sought help & & & & $50 \%$ & & \\
\hline Previously received help & & & & $62 \%$ & & \\
\hline Currently receives help & & & & $77 \%$ & & \\
\hline Desires help & & & & $17 \%$ & & \\
\hline \multicolumn{7}{|l|}{ Sexual functioning (FSFI) } \\
\hline Sexual desire & $3.5(1.1)^{*}$ & & $3.0(1.4)^{*}$ & & $3.3(1.3)$ & \\
\hline Sexual arousal & $3.7(1.9)$ & & $3.0(1.5)$ & & $3.3(1.7)$ & \\
\hline Lubrication & $4.4(1.6)$ & & $3.0(1.3)$ & & $3.7(1.6)$ & \\
\hline Orgasmic functioning & $4.1(1.6)$ & & $3.4(1.3)$ & & $3.8(1.5)$ & \\
\hline Sexual satisfaction & $4.5(1.4)^{* *}$ & & $3.2(1.2)^{* *}$ & & $3.9(1.5)$ & \\
\hline Sexual pain & $4.2(1.8)^{* *}$ & & $2.9(1.8)^{* *}$ & & $3.5(1.9)$ & \\
\hline FSFI total score & $25.1(5.9)^{* *}$ & & $18.6(5.0)^{* *}$ & & $21.8(6.3)$ & \\
\hline \multicolumn{7}{|l|}{ Sexual distress (FSDS) } \\
\hline Total FSDS score & $7.3(8.6)^{* * *}$ & & $24.3(8.1)^{* * *}$ & & $15.5(12.0)$ & \\
\hline
\end{tabular}

$* p<.05 ; * * p<.01 ; * * * p<.001 ;{ }^{\text {a }}$ sum exceeds $100 \%$ due to comorbid self-reported sexual problems

Univariate comparisons showed that nonsymptomatic women harbored significantly stronger implicit associations of erotic stimuli with wanting than women with sexual problems, $t(69)=-2.01, p<.05$, and their explicit ratings of the erotic stimuli were more positive, $t(63)=2.85, p<.01$. Both groups did not differ with regard to implicit liking $(p>.05)$. 
A MANOVA was performed with ST-IAT liking and wanting scores and EEES sum scores as dependent variables and sexual function status as fixed factor. After deletion of the univariate outliers and cases with missing values, 58 cases were left for analysis. A significant multivariate effect was found, $F(3,54)=5.6, p=.002$, partial $\eta^{2}=.24$. Follow-up testing revealed significant effects of ST-IAT wanting, $F(1$, $56)=9.8, p=.003$, partial $\eta^{2}=.15$, and of the explicit ratings, $F(1,56)=7.5, p=.008$, partial $\eta^{2}=.12$, whereas the effect of ST-IAT liking was not significant, $F(1,56)=0.4$, $p=.85$, partial $\eta^{2}=.001$. Compared to women with sexual problems, nonsymptomatic participants had more negative ST-IAT wanting scores, indicating stronger implicit wanting of erotic stimuli. Women in both groups had similarly negative ST-IAT liking scores, indicating positive implicit associations of erotic stimuli in both groups.

Table 3 Bivariate correlations between implicit and explicit associations of erotic stimuli with valence and motivation

\begin{tabular}{llll}
\hline & D600 liking & D600 wanting & EEES \\
\hline D600 liking & - & & \\
D600 wanting & .08 & - & \\
EEES & .03 & -.18 & - \\
\hline
\end{tabular}

\section{Associations of Implicit and Explicit Cognitions with Continuous Measures of Sexual Functioning and Sexual Distress}

Hierarchical linear regression analyses (Enter method) were performed with, respectively, level of sexual functioning (FSFI total score), and sexual distress (FSDS scores) as dependent variables, and with ST-IAT liking and wanting indices, and EEES sum scores as independent variables. The assumptions of normality, linearity, and collinearity, and the presence of outliers were evaluated; no violations were identified. In total, 58 cases were retained for analysis. A linear regression analysis was performed with FSFI total scores as to-be-predicted variable and ST-IAT liking and wanting scores and EEES sum scores as predictor variables revealed a significant regression model compared to a constant-only model, $R^{2}=.16, F(3,49)=3.1, p=.034$; see Table 5. Implicit wanting contributed significantly to the model, $\beta=-.31$, $p=.024$. High implicit wanting (more negative D600 STIAT) scores were found to predict high levels of sexual functioning. A regression model with level of sexual distress (FSDS total score) as criterion variable and ST-IAT liking and wanting scores and EEES sum scores as predictor variables was also significant, $R^{2}=.15, F(3,54)=3.1, p=.036$; see Table 6. Only explicit ratings contributed significantly to the

Table 4 Implicit and explicit cognitions in women with and without sexual problem $(N=73)$

\begin{tabular}{|c|c|c|c|c|c|c|}
\hline & \multicolumn{2}{|c|}{ D600 liking } & \multicolumn{2}{|c|}{ D600 wanting } & \multicolumn{2}{|c|}{ EEES sum score } \\
\hline & $M$ & SD & $M$ & SD & $M$ & SD \\
\hline \multicolumn{7}{|c|}{ Sexual problem } \\
\hline No & -.12 & .36 & $-.16^{*}$ & .37 & $3.61 * *$ & .76 \\
\hline Yes & -.12 & .39 & $.02 *$ & .37 & $3.04 * *$ & .85 \\
\hline
\end{tabular}

$* p<.05 ; * * p<.01$

Table 5 Linear regression model of implicit liking, implicit wanting, and explicit ratings of erotic stimuli on global sexual functioning

\begin{tabular}{lrrrrrr}
\hline Predictor variables & B & SE & Beta & $t$ & $p$ & \multicolumn{1}{c}{ 95\% CI } \\
\hline (Constant) & -.22 & .14 & .10 & -1.59 & .12 & -.51 \\
ST-IAT liking & .26 & .34 & -.31 & .78 & .44 & -.41 \\
ST-IAT wanting & -.81 & .35 & .19 & -2.33 & .02 & -1.50 \\
EEES & .22 & .15 & & 1.46 & .15 & -.08 \\
\hline
\end{tabular}

FSFI total score

Table 6 Linear regression model of implicit liking, implicit wanting, and explicit ratings of erotic stimuli on sexual distress

\begin{tabular}{lccrrrr}
\hline Predictor variables & B & SE & Beta & $t$ & $p$ & \multicolumn{1}{c}{$95 \%$ CI } \\
\hline (Constant) & .25 & .14 & .09 & 1.74 & .09 & -.04 \\
ST-IAT liking & .24 & .33 & .21 & .73 & .47 & -.42 \\
ST-IAT wanting & .57 & .35 & -.28 & 1.64 & .11 & -.13 \\
EEES & -.32 & .15 & & -2.20 & .03 & -.62 \\
\hline
\end{tabular}

FSDS score 
model, $\beta=-.28, p=.032$. More positive explicit ratings of the erotic stimuli predicted lower level of sexual distress.

\section{Discussion}

In this study implicit and explicit cognitions were compared in women with and without sexual problems. At the group level, women with sexual problems were found to have more negative implicit associations of erotic stimuli with wanting than nonsymptomatic women, but they did not differ regarding their implicit liking of erotic stimuli. Compared with nonsymptomatic women, women with sexual problems also explicitly rated erotic pictures used in the ST-IAT computer tasks as less positive. At the individual level, implicit wanting was found to predict level of sexual functioning. Explicit cognition significantly predicted level of sexual distress. Correlations between implicit measures of liking and wanting and explicit ratings in the present study were nonsignificant. This finding is in line with the low or absent correlations between these measures found in other populations (see for a review and a meta-analysis: Hofmann, Gawronski, Gschwendner, Le, \& Schmitt, 2005; Tibboel, De Houwer, \& Van Bockstaele, 2015).

The current finding of significant differences in the explicit appraisal of erotic stimuli between women with and without sexual problems replicates previous research into the role of explicit cognitions in sexual functioning (Andersen et al., 1999; Nobre \& Pinto-Gouveia, 2009; Peixoto \& Nobre, 2014, 2016; Quinta Gomes \& Nobre, 2012). The current findings with regard to group differences are also partly in line with previous study findings in women and men using single-target IATs, although direct comparisons are not possible, due to method and sample differences. Our finding that sexual distress was significantly predicted by participant's explicit ratings of the erotic pictures, with positive ratings associated with higher levels of sexual distress, replicates research using the same methodology in a sample of male urological patients with and without sexual dysfunction (van Lankveld et al., 2015). The level of discomfort and bother associated with sexual problems was not significantly predicted by implicit sexual cognitions.

Implicit liking did not distinguish between women with and without sexual problems in the present study among women with various types of sexual complaints, whereas Borg et al. (2010) — in contrast—found stronger automatic sex-disgust associations in women with sexual pain disorders compared to healthy women and Brauer et al. (2011) found weaker associations of erotic pictures with positive valence in women with hypoactive sexual desire disorder compared to healthy women. Differences between women with and without sexual problems regarding their implicit sexual motivation (wanting) that were revealed in the present study have, as far as we know, not been previously investigated.
The demonstration of differential responding of women with and without sexual problems with respect to their implicit wanting associations with erotic stimuli supports the information-processing model of sexual functioning (Janssen et al., 2000), in as far as it postulates the involvement of automatic processing in the generation of sexual arousal, in addition to controlled cognitive processing. The observed difference between women with and without sexual problem on the wanting ST-IAT and the absence of differences between these groups regarding implicit liking of erotic stimuli, however, remains open to various interpretations. Implicit attitudes have been suggested to reveal both deeply ingrained cultural traditions (Nosek et al., 2009; Steffens \& Buchner, 2003) and the result of learning experiences in individual personal history (Gonzalez et al., 2016). One could argue that problematic sexual functioning (e.g., low sexual desire before or during sexual activity, not becoming sexually aroused, absent, or inconsistent orgasm) provides women with negative experiences that might also have learning effects and thus lower their motivation for future sexual approach behavior. This could be reflected in more negative implicit associations of erotic stimuli with wanting. However, this does not seem to explain the unshattered positive implicit liking associations with erotic stimuli in the same women, based on the assumption that implicit liking would be subject to the same evaluative learning mechanism that would change implicit wanting (Mitchell, Anderson, \& Lovibond, 2003). However, Robinson and Berridge $(1993,2008)$ postulate in their incentive-sensitization theory that, in the context of drug addiction, drug "wanting" and drug "liking" do not necessarily coincide. Although a person may, over the course of his drug use history, stop pursuing drug use due to the waning of the drug's euphoric effects ("liking"), he may, nevertheless, experience craving for the drug as a result of the incentivemotivational ("wanting") properties that the drug itself and the stimuli associated with it have acquired. Obviously, the present study design precludes any inferences about causal relationships between implicit attitudes and motivation and sexual dysfunction; both could serve as cause and as effect, and a circular connection is also plausible.

The discrepancies between the implicit cognitive patterns thus far found in women and men are puzzling. Whereas women with and without sexual problem in the present study could be distinguished by their implicit sexual wanting scores, previous studies among men with and without sexual dysfunctions found, in contrast, that implicit liking associations discriminated between both group, while implicit wanting scores in both male groups were equal (van Lankveld et al., 2015, 2017). Research in which men and women are directly compared is necessary to investigate potential explanations for this gender difference.

The current findings may have implications for sexual health care. The observed association between explicit liking 
of erotic stimuli and level of sexual distress can be taken to suggest that instigating more positive explicit appraisals of erotic stimuli, using cognitive restructuring techniques (e.g., ter Kuile, Both, \& van Lankveld, 2010), might lower the distress associated with sexual problems of women with sexual problems, even though it might not improve the functional aspects of sexual responding. Low implicit wanting of erotic stimuli that was found to be associated with sexual problems in the present study may not be directly affected using cognitive interventions. Implicit, automatic associations are often considered to develop early in human life and to change only slowly as a result of repeated exposure or rehearsal (Gonzalez et al., 2016; Houben, Havermans, \& Wiers, 2010). However, the existence of both trait and context-dependent state aspects of implicit cognition has been demonstrated (Steffens \& Buchner, 2003), and implicit attitudes were shown to be malleable (Houben et al., 2010). This suggests that future research into the modification of implicit attitudes and motivation can be useful.

Some limitations of the present study should be acknowledged. The low levels of anxiety and depression (HADS) that were found in the present study sample may have been due to self-selection that is typical for research into sexuality (Plaud, Gaither, Hegstad, Rowan, \& Devitt, 1999). In future studies larger and more representative samples should be investigated to examine whether the present findings also hold true in older women and in women with lower mental health level. The sample characteristics of participants in the present study, who were all recruited in an outpatient clinic for gynecology, limit the generalization of findings to other populations. Replication of the study in nongynecological samples of women with and without sexual problems is necessary for this purpose. Finally, the laboratory setting of the present study does not allow for generalization of the observed associations to the daily context of sexual activity (Bloemers et al., 2010; van Lankveld et al., 2014).

Acknowledgements We kindly thank Dr. Sandra Stekelenburg and Dr. Jan Schram, gynecologists, and Joke van Ommen en Els van Oevelen, pelvic floor physiotherapists, for their participation in the recruitment of participants in this study.

Open Access This article is distributed under the terms of the Creative Commons Attribution 4.0 International License (http://creativecommons.org/licenses/by/4.0/), which permits unrestricted use, distribution, and reproduction in any medium, provided you give appropriate credit to the original author(s) and the source, provide a link to the Creative Commons license, and indicate if changes were made.

\section{References}

Abrahamson, D. J., Barlow, D. H., \& Abrahamson, L. S. (1989). Differential effects of performance demand and distraction on sexually functional and dysfunctional males. Journal of Abnormal Psychology, 98, 241-247.
Abrahamson, D. J., Barlow, D. H., Sakheim, D. K., Beck, J. G., \& Athanasiou, R. (1985). Effects of distraction on sexual responding in functional and dysfunctional men. Behavior Therapy, 16, 503-515. https://doi.org/10.1016/S0005-7894(85)80028-9.

Adams, A. E., 3rd, Haynes, S. N., \& Brayer, M. A. (1985). Cognitive distraction in female sexual arousal. Psychophysiology, 22, 689-696. https://doi.org/10.1111/j.1469-8986.1985.tb01669.x.

Andersen, B. L., Cyranowski, J. M., \& Espindle, D. (1999). Men's sexual self-schema. Journal of Personality and Social Psychology, 76, 645-661. https://doi.org/10.1037/0022-3514.76.4.645.

Bach, A. K., Brown, T. A., \& Barlow, D. H. (1999). The effects of false negative feedback on efficacy expectancies and sexual arousal in sexually functional males. Behavior Therapy, 30, 79-95. https:// doi.org/10.1016/S0005-7894(99)80047-1.

Baddeley, A. (1992). Working memory. Science, 255, 556-559. https:// doi.org/10.1126/science.1736359.

Barlow, D. H. (1986). Causes of sexual dysfunction: The role of anxiety and cognitive interference. Journal of Consulting and Clinical Psychology, 54, 140-148. https://doi.org/10.1037/0022-006X.54.2.140.

Barlow, D. H., Sakheim, D. K., \& Beck, J. G. (1983). Anxiety increases sexual arousal. Journal of Abnormal Psychology, 92, 49-54.

Beck, J. G., \& Barlow, D. H. (1986a). The effects of anxiety and attentional focus on sexual responding-I. Physiological patterns in erectile dysfunction. Behaviour Research and Therapy, 24, 9-17. https://doi.org/10.1016/0005-7967(86)90144-0.

Beck, J. G., \& Barlow, D. H. (1986b). The effects of anxiety and attentional focus on sexual responding-II. Cognitive and affective patterns in erectile dysfunction. Behaviour Research and Therapy, 24, 19-26.

Bloemers, J., Gerritsen, J., Bults, R., Koppeschaar, H., Everaerd, W., Olivier, B., \& Tuiten, A. (2010). Induction of sexual arousal in women under conditions of institutional and ambulatory laboratory circumstances: A comparative study. Journal of Sexual Medicine, 7, 1160-1176.

Bluemke, M., \& Friese, M. (2008). Reliability and validity of the singletarget IAT (ST-IAT): Assessing automatic affect towards multiple attitude objects. European Journal of Social Psychology, 38, 977-997. https://doi.org/10.1002/ejsp.487.

Borg, C., de Jong, P. J., \& Weijmar Schultz, W. (2010). Vaginismus and dyspareunia: Automatic vs. deliberate disgust responsivity. Journal of Sexual Medicine, 7, 2149-2157. https://doi.org/ 10.1111/j.1743-6109.2010.01800.x.

Brauer, M., van Leeuwen, M., Janssen, E., Newhouse, S. K., Heiman, J. R., \& Laan, E. (2011). Attentional and affective processing of sexual stimuli in women with hypoactive sexual desire disorder. Archives of Sexual Behavior, 41, 891-905. https://doi.org/10.1007/ s10508-011-9820-7.

Corr, P. J. (2010). Automatic and controlled processes in behavioural control: Implications for personality psychology. European Journal of Personality, 24, 376-403. https://doi.org/10.1002/per.779.

de Jong, D. C. (2009). The role of attention in sexual arousal: Implications for treatment of sexual dysfunction. Journal of Sex Research, 46, 237-248. https://doi.org/10.1080/00224490902747230.

Dehaene, S. (2014). Consciousness and the brain: Deciphering how the brain codes our thoughts. New York: Viking.

Derogatis, L. R., Rosen, R., Leiblum, S., Burnett, A., \& Heiman, J. (2002). The Female Sexual Distress Scale (FSDS): Initial validation of a standardized scale for assessment of sexually related personal distress in women. Journal of Sex and Marital Therapy, 28, 317-330. https://doi.org/10.1080/00926230290001448.

Elliott, A. N., \& O'Donohue, W. T. (1997). The effects of anxiety and distraction on sexual arousal in a nonclinical sample of heterosexual women. Archives of Sexual Behavior, 26, 607-624. https:// doi.org/10.1023/A:1024524326105.

Evans, J., \& Frankish, K. (2009). In two minds: Dual processes and beyond. New York: Oxford University Press. 
Fitousi, D., \& Wenger, M. J. (2011). Processing capacity under perceptual and cognitive load: A closer look at load theory. Journal of Experimental Psychology: Human Perception and Performance, 37, 781-798. https://doi.org/10.1037/a0020675.

Gawronski, B., \& Bodenhausen, G. V. (2006). Associative and propositional processes in evaluation: An integrative review of implicit and explicit attitude change. Psychological Bulletin, 132, 692-731. https://doi.org/10.1037/0033-2909.132.5.692.

Geer, J. H., \& Fuhr, R. (1976). Cognitive factors in sexual arousal: The role of distraction. Journal of Consulting and Clinical Psychology, 44, 238-243. https://doi.org/10.1037/0022-006X.44.2.238.

Gonzalez, A. M., Dunlop, W. L., \& Baron, A. S. (2017). Malleability of implicit associations across development. Developmental Science. https://doi.org/10.1111/desc.12481.

Greenwald, A. G., McGhee, D. E., \& Schwartz, J. L. (1998). Measuring individual differences in implicit cognition: The Implicit Association Test. Journal of Personality and Social Psychology, 74, 1464-1480. https://doi.org/10.1037/0022-3514.74.6.1464.

Greenwald, A. G., Nosek, B. A., \& Banaji, M. R. (2003). Understanding and using the Implicit Association Test: I. An improved scoring algorithm. Journal of Personality and Social Psychology, 85, 197-216. https://doi.org/10.1037/0022-3514.85.2.197.

Hofmann, W., \& Friese, M. (2008). Impulses got the better of me: Alcohol moderates the influence of implicit attitudes toward food cues on eating behavior. Journal of Abnormal Psychology, 117, 420-427. https://doi.org/10.1037/0021-843X.117.2.420.

Hofmann, W., Gawronski, B., Gschwendner, T., Le, H., \& Schmitt, M. (2005). A meta-analysis on the correlation between the Implicit Association Test and explicit self-report measures. Personality and Social Psychology Bulletin, 31, 1369-1385. https://doi. org/10.1177/0146167205275613.

Houben, K., Havermans, R. C., \& Wiers, R. W. (2010). Learning to dislike alcohol: Conditioning negative implicit attitudes toward alcohol and its effect on drinking behavior. Psychopharmacology (Berl), 211, 79-86. https://doi.org/10.1007/s00213-010-1872-1.

Houben, K., \& Wiers, R. W. (2008). Measuring implicit alcohol associations via the Internet: Validation of web-based Implicit Association Tests. Behavior Research Methods, Instruments, \& Computers, 40, 1134-1143. https://doi.org/10.3758/BRM.40.4.1134.

Janssen, E., Everaerd, W., Spiering, M., \& Janssen, J. (2000). Automatic processes and the appraisal of sexual stimuli: Toward an information processing model of sexual arousal. Journal of Sex Research, 37, 8-23. https://doi.org/10.1080/00224490009552016.

Janssen, E., Everaerd, W., Van Lunsen, R. H., \& Oerlemans, S. (1994). Validation of a psychophysiological waking erectile assessment (WEA) for the diagnosis of male erectile disorder. Urology, 43, 686-695. https://doi.org/10.1016/0090-4295(94)90185-6.

Kahneman, D. (1973). Attention and effort. Englewood Cliffs, NJ: Prentice Hall.

Karpinski, A., \& Steinman, R. B. (2006). The Single Category Implicit Association Test as a measure of implicit social cognition. Journal of Personality and Social Pychology, 91, 16-32. https://doi. org/10.1037/0022-3514.91.1.16.

Laan, E., \& Everaerd, W. (1995). Determinants of female sexual arousal: Psychophysiological theory and data. Annual Review of Sex Research, 6, 32-76.

Lang, P. J., Bradley, M. M., \& Cuthbert, B. N. (1999). International Affective Picture System (IAPS): Technical manual and affective ratings. Gainesville, FL: The Center for Research in Psychophysiology, University of Florida.

Macapagal, K. R., \& Janssen, E. (2011). The valence of sex: Automatic affective associations in erotophilia and erotophobia. Personality and Individual Differences, 51, 699-703. https://doi.org/10.1016/j. paid.2011.06.008.

Mitchell, C. J., Anderson, N. E., \& Lovibond, P. F. (2003). Measuring evaluative conditioning using the Implicit Association Test.
Learning and Motivation, 34, 203-217. https://doi.org/10.1016/ S0023-9690(03)00003-1.

Mitchell, W. B., DiBartolo, P. M., Brown, T. A., \& Barlow, D. H. (1998). Effects of positive and negative mood on sexual arousal in sexually functional males. Archives of Sexual Behavior, 27, 197-207.

Nobre, P. J., \& Pinto-Gouveia, J. (2009). Cognitive schemas associated with negative sexual events: A comparison of men and women with and without sexual dysfunction. Archives of Sexual Behavior, 38, 842-851. https://doi.org/10.1007/s10508-008-9450-x.

Nosek, B. A., Greenwald, A. G., \& Banaji, M. R. (2005). Understanding and using the Implicit Association Test: II. Method variables and construct validity. Personality and Social Psychology Bulletin, 31, 166-180. https://doi.org/10.1177/0146167204271418.

Nosek, B. A., Smyth, F. L., Sriram, N., Lindner, N. M., Devos, T., Ayala, A., ... Greenwald, A. G. (2009). National differences in gender-science stereotypes predict national sex differences in science and math achievement. Proceedings of the National Academy of Sciences of the United States of America, 106, 10593-10597. https://doi.org/10.1073/ pnas.0809921106.

Olson, M. A., \& Fazio, R. H. (2004). Reducing the influence of extrapersonal associations on the Implicit Association Test: Personalizing the IAT. Journal of Personality and Social Psychology, 86, 653-667. https://doi.org/10.1037/0022-3514.86.5.653.

Opperman, E. A., Benson, L. E., \& Milhausen, R. R. (2013). Confirmatory factor analysis of the Female Sexual Function Index. Journal of Sex Research, 50, 29-36. https://doi.org/10.1080/00224499.2011.628423.

Peixoto, M. M., \& Nobre, P. (2014). Dysfunctional sexual beliefs: A comparative study of heterosexual men and women, gay men, and lesbian women with and without sexual problems. Journal of Sexual Medicine, 11, 2690-2700. https://doi.org/10.1111/jsm.12666.

Peixoto, M. M., \& Nobre, P. J. (2016). Automatic thoughts during sexual activity, distressing sexual symptoms, and sexual orientation: Findings from a web survey. Journal of Sex and Marital Therapy, 42, 616-634. https://doi.org/10.1080/0092623X.2015.1113583.

Plaud, J. J., Gaither, G. A., Hegstad, H. J., Rowan, L., \& Devitt, M. K. (1999). Volunteer bias in human psychophysiological sexual arousal research: To whom do our research results apply? Journal of Sex Research, 36, 171-179. https://doi.org/10.1080/00224499909551982.

Quinta Gomes, A. L., \& Nobre, P. (2012). Early maladaptive schemas and sexual dysfunction in men. Archives of Sexual Behavior, 41, 311-320.

Robinson, T. E., \& Berridge, K. C. (1993). The neural basis of drug craving: An incentive-sensitization theory of addiction. Brain Research. Brain Research Reviews, 18, 247-291. https://doi.org/ 10.1016/0165-0173(93)90013-P.

Robinson, T. E., \& Berridge, K. C. (2008). The incentive sensitization theory of addiction: Some current issues. Philosophical Transactions of the Royal Society of London. Series B, Biological Sciences, 363, 3137-3146. https://doi.org/10.1098/rstb.2008.0093.

Roefs, A., Huijding, J., Smulders, F. T., MacLeod, C. M., de Jong, P. J., Wiers, R. W., \& Jansen, A. T. (2011). Implicit measures of association in psychopathology research. Psychological Bulletin, 137, 149-193. https://doi.org/10.1037/a0021729.

Romer Thomsen, K., Whybrow, P. C., \& Kringelbach, M. L. (2015). Reconceptualizing anhedonia: Novel perspectives on balancing the pleasure networks in the human brain. Frontiers in Behavioral Neuroscience, 9, 49. https://doi.org/10.3389/fnbeh.2015.00049.

Rosen, R., Brown, C., Heiman, J., Leiblum, S., Meston, C., Shabsigh, R., ... D'Agostino, R., Jr. (2000). The Female Sexual Function Index (FSFI): A multidimensional self-report instrument for the assessment of female sexual function. Journal of Sex and Marital Therapy, 26, 191-208. https://doi.org/10.1080/009262300278597.

Salemink, E., \& van Lankveld, J. J. (2006). The effects of increasing neutral distraction on sexual responding in women with and without sexual problems. Archives of Sexual Behavior, 35, 179-190. https://doi.org/10.1007/s10508-005-9014-2. 
Schneider, W., \& Shiffrin, R. M. (1977). Controlled and automatic human information processing: I. Detection, search, and attention. Psychological Review, 84, 1-66. https://doi.org/10.1037/0033-295X.84.1.1.

Spiering, M., Everaerd, W., \& Janssen, E. (2003). Priming the sexual system: Implicit versus explicit activation. Journal of Sex Research, 40, 134-145. https://doi.org/10.1080/00224490309552175.

Spiering, M., Everaerd, W., Karsdorp, P., Both, S., \& Brauer, M. (2006). Nonconscious processing of sexual information: A generalization to women. Journal of Sex Research, 43, 268-281. https://doi. org/10.1080/00224490609552325.

Spinhoven, P., Ormel, J., Sloekers, P. P., Kempen, G. I., Speckens, A. E., \& Van Hemert, A. M. (1997). A validation study of the Hospital Anxiety and Depression Scale (HADS) in different groups of Dutch subjects. Psychological Medicine, 27, 363-370. https://doi. org/10.1017/S0033291796004382.

Steffens, M. C., \& Buchner, A. (2003). Implicit Association Test: Separating transsituationally stable and variable components of attitudes toward gay men. Experimental Psychology, 50, 33-48. https://doi. org/10.1027//1618-3169.50.1.33.

Steiger, J. H. (2004). Beyond the F test: Effect size confidence intervals and tests of close fit in the analysis of variance and contrast analysis. Psychological Methods, 9, 164-182. https://doi. org/10.1037/1082-989X.9.2.164.

Strack, F., \& Deutsch, R. (2004). Reflective and impulsive determinants of social behavior. Personality and Social Psychology Review, 8, 220-247. https://doi.org/10.1207/s15327957pspr0803_1.

ter Kuile, M. M., Both, S., \& van Lankveld, J. (2010). Cognitive behavioral therapy for sexual dysfunctions in women. Psychiatric Clinics of North America, 33, 595-610. https://doi.org/10.1016/j. psc.2010.04.010.

ter Kuile, M. M., Brauer, M., \& Laan, E. (2006). The Female Sexual Function Index (FSFI) and the Female Sexual Distress Scale (FSDS): Psychometric properties within a Dutch population. Journal of Sex and Marital Therapy, 32, 289-304. https://doi. org/10.1080/00926230600666261.

Tibboel, H., De Houwer, J., Spruyt, A., Field, M., Kemps, E., \& Crombez, G. (2011). Testing the validity of implicit measures of wanting and liking. Journal of Behavior Therapy and Experimental Psychiatry, 42, 284-292. https://doi.org/10.1016/j.jbtep.2011.01.002.

Tibboel, H., De Houwer, J., \& Van Bockstaele, B. (2015). Implicit measures of 'wanting' and 'liking' in humans. Neuroscience and Biobehavioral Reviews, 57, 350-364. https://doi.org/10.1016/j. neubiorev.2015.09.015.

van Lankveld, J. (2010). Attentional mechanisms in sexual arousal and sexual dysfunction: A review and new data. Paper presented at the 10th Congress of the European Federation of Sexology, Porto, Portugal.

van Lankveld, J., \& Bergh, S. (2008). The interaction of state and trait aspects of self-focused attention affects genital, but not subjective, sexual arousal in sexually functional women. Behaviour Research and Therapy, 46, 514-528. https://doi.org/10.1016/j. brat.2008.01.017.

van Lankveld, J. J. D. M., de Jong, P. J., Henckens, M. J. M. J., den Hollander, P., van den Hout, A. J. H. C., \& de Vries, P. (2017). Automatic sex-liking and sex-failure associations in men with sexual dysfunction. Journal of Sex Research. https://doi.org/10.1080/00 224499.2017.1394960.

van Lankveld, J., Hubben, D., Dewitte, M., Dingemans, M. E., den Butter, C., \& Grauvogl, A. (2014). The partner's presence in the sex research lab differentially affects sexual arousal in women and men. Journal of Sexual Medicine, 11, 697-708. https://doi. org/10.1111/jsm. 12406.

van Lankveld, J., Odekerken, I., Kok-Verhoeven, L., van Hooren, S., de Vries, P., van den Hout, A., \& Verboon, P. (2015). Implicit and explicit associations with erotic stimuli in sexually functional and dysfunctional men. Journal of Sexual Medicine, 12, 1791-1804. https://doi.org/10.1111/jsm.12930.

van Lankveld, J., \& van den Hout, M. A. (2004). Increasing neutral distraction inhibits genital but not subjective sexual arousal of sexually functional and dysfunctional men. Archives of Sexual Behavior, 33, 549-558. https://doi.org/10.1023/B:ASEB.0000044739.29113.73.

van Lankveld, J., \& van den Hout, M. A. (2005). Aandachtsprocessen bij genitale seksuele opwinding: Een etiologisch model van seksuele opwindingsstoornissen [Attentional processes in genital sexual arousal: An etiological model of sexual arousal disorders]. Tijdschrift voor Seksuologie, 29, 69-81.

Weisberg, R. B., Bach, A. K., \& Barlow, D. H. (1995). Sexually functional and dysfunctional males' attributions for erectile performance during a physiological measurement session. Paper presented at the annual convention of the Association for the Advancement of Behavior Therapy, Washington, DC.

Wiegel, M., Scepkowski, L. A., \& Barlow, D. H. (2007). Cognitiveaffective processes in sexual arousal and sexual dysfunction. In E. Janssen (Ed.), The psychophysiology of sex (pp. 143-165). Bloomington, IN: Indiana University Press.

Zigmond, A. S., \& Snaith, R. P. (1983). The Hospital Anxiety and Depression Scale. Acta Psychiatrica Scandinavica, 67, 361-370. https://doi.org/10.1111/j.1600-0447.1983.tb09716.x. 